\title{
De paseo por el crimen Género y trayecto del policial en la pantalla chica
}

\author{
Giancarlo Cappello \\ Universidad de Lima \\ Recibido: 6/9/2010 \\ Aceptado: 17/11/2010
}

\begin{abstract}
Resumen: Se abordan los inicios del policial en la literatura y su continuación en la pantalla chica. La dinámica de narración de un género que se reinventa a partir de sus nexos con la cultura popular. En síntesis, es un ensayo orientado a recuperar la historia del género policial desde su desarrollo auroral en la literatura de Edgard Allan Poe hasta su trasvase a series televisivas como Columbo, Kojak, Miami Vice, Cagney \& Lacey, CSI, NYPD Blue o The Wire. El énfasis está puesto en el análisis del comportamiento de los relatos policiales con relación a los cambios de época, los contextos sociales y los vínculos que este género ha cultivado con la cultura popular a lo largo de su historia.
\end{abstract}

Palabras clave: Género / series de televisión / policial

\section{Walk through the crime}

Genre and course of policier on the small screen

Summary: The beginnings of policier in the literature and then on the small screen. The dynamics of narrative that is reinventing a genre from its connections with popular culture. In summary, this essay is designed to recover the history of the detective genre since its development in the auroral literature of Edgar Allan Poe to its transfer to television series such as Columbo, Kojak, Miami Vice, Cagney \& Lacey, CSI, NYPD Blue or The Wire. The emphasis is put on the analysis of the behavior of police reports in relation to changes in time, social contexts and the links that this genre has grown in popular culture throughout history.

Keywords: Genre / TV series / policier (cop films) 


\section{Las circunstancias del crimen}

$\mathrm{T}$ odo parece indicar que la aparición en 1841 de un extraño la calle Morgue, firmado por Edgard Allan Poe, fue el detonante de un relato que irrumpió con un influjo casi mágico. Cuenta la leyenda que Poe leía la narración de un crimen en la novela de Dickens Barnaby Rudge, cuando a poco de iniciar su lectura descifró el enigma. Reflexionando acerca del procedimiento que había utilizado, dio con las reglas del relato policial y las aplicó en el relato mencionado y en una serie de cuentos, como La carta robada y El asesinato de Marie Roget, que pronto encandilaron a los lectores. $\mathrm{Si}$ bien el germen de estos textos había sido tomado del libro de memorias de François Vidoq, fundador de la primera agencia de detectives de París, Poe combinó los recursos de la literatura y el racionalismo filosófico para obtener un cóctel artístico que ahora puede parecer tremendamente común, pero que fundó todo un género representativo del mundo moderno, donde un hecho misterioso, aparentemente inexplicable o sobrenatural, se resolvía a manos (y mente, sobre todo) de un individuo con vocación de científico y detective.

Si el policial provocó revuelo fue porque sintonizó inmediatamente con el nuevo tiempo que empezaba a vivirse. Un tiempo donde el romanticismo, que entendía lo misterioso como una especie de más allá de las cosas, accesible solo a fuerza de sensibilidad y corazón, se desmoronaba ante las ideas de Auguste Comte, que entendía la vida más bien como materia $\mathrm{y}$, por consiguiente, como un espacio perteneciente a la ciencia, dejando afuera el ocultismo, lo inexpugnable y la magia. Un tiempo donde la industrialización alcanzaba cotas muy altas, apoyada por el avance técnico y científico, y donde el racionalismo lo impregnaba todo, desde el marxismo hasta el positivismo que se extendió hasta entrado el siglo XX.

Así, el misterio pasó a llamarse hecho insólito y apareció el crimen, aquello que contravenía las reglas, la homeostasis, el equilibrio social, tal cual se publicaba en los periódicos "convertido en espectáculo, con sus ribetes de fantasía y sangre" (Brunori 1980). De otro lado, las condiciones filosóficas que instauraron la deducción y la inducción como herramientas claves, y el paso firme de la ciencia en los campos de la poligrafía y el análisis de rastros, se encargaron de articular el relato en clave de investigación. El policial conjugó folletín y ciencia y, de esta manera, se convirtió en emblema contra los fantasmas de lo impenetrable. A partir de entonces, la razón tendría siempre las de ganar.

\section{Un tipo marginal}

El policial ha coqueteado desde siempre con los márgenes, como si las etiquetas redondas le disgustaran tanto 
como los trajes entallados. Si bien es el resultado de una circunstancia particular del culto a la razón, sus orígenes tienen que ver más con cierto antirrealismo que con una asociación incorruptible con la verosimilitud. $\mathrm{Si}$ se observa con atención, el juego que propone busca deconstruir un aparato ideal. Es decir, para que el policial funcione se necesita la consumación de un crimen inescrutable, misterioso, casi perfecto, al que se confronta otro elemento ideal, un hombre superdotado, raro entre miles, con una inteligencia no convencional, capaz de articular inducción, deducción y una vocación de científico y ratón de biblioteca. Este tipo de relato crea universos propios regidos por leyes científicas afectadas solo por la fantasía convenientemente administrada del escritor, que propone, de modo invariable, la victoria del orden y la justicia sobre el crimen y la maldad. ${ }^{1}$ Sherlock Holmes, le chevalier Dupin y father Brown son los exponentes más notables.

Tendrían que pasar varios años para que este canon experimente un cambio radical. Tendría que llegar el siglo XX y aparecer Dashiell Hammett para arrojar ese viejo jarrón veneciano a la mugre de la calles, como reza una de las frases más conocidas de Raymond Chandler. Y no es casual que ocurriera en los Estados Unidos y en la década del treinta, ya que la realidad del gran crac de 1929 colocó a los escritores de bruces en la acera, donde la literatura realista y social venía más a tono frente a los distintos síntomas de crisis de una sociedad industrial que había dado lugar al nacimiento del fascismo y el socialismo soviético y apuntaba a una crisis mayor que se llamaría Segunda Guerra Mundial. En adelante, el hard boiled story trasladaría el crimen a escenarios más pertinentes, como las inasibles ciudades del Nuevo Mundo donde el enigma es sucio, básicamente vulgar, lejos del positivismo lógico y apostando por renovar los agotados procedimientos del policial clásico con nuevas técnicas, más mundanas y menos estilizadas, como una soberana pateadura al tipo del cual se pueden obtener buenas pistas para resolver el caso.

El halcón maltés delinea, de alguna manera, los nuevos modos del relato policial, instaurándose como el arquetipo que se debe seguir. Allí hace su aparición el nuevo investigador, ya no un intelectual infalible, sino más bien un sujeto cínico, ácido, caradura e impredecible como el californiano Sam Spade, sin amigos y de moral ambigua. Estos nuevos relatos desentrañarán otro tipo de misterios, crímenes más terrenos, desde asesinatos hasta robos, extorsiones, chantajes y contra-

1 Estos mundos se parecen mucho a los clásicos problemas de física que proponen los maestros de escuela, donde hay que averiguar pesos y velocidades en un 'universo vacío', omitiendo fuerzas de rozamiento y otras variables atmosféricas que afectan a cualquier fenómeno en el mundo real. 
bando. El nuevo héroe se tiñe de soledad e incomunicación, como el espectro vagabundo de muchos ciudadanos devorados por las ciudades contemporáneas. Su tono realista y eminentemente urbano conectó con el espíritu de la época, de hecho, el policial vivió una época dorada: saltó de los libros a los diarios, a los cómics, a los paperbacks y los pulps. A fines de los años treinta su serialidad ya se pautaba según la industria libresca, que incluyó novedades para su actualización, por ejemplo el personaje del mago, el vidente, o algún psíquico, quizá como ecos de la infuencia que el piscoanálisis empezaba a obrar (Symons 1982).

El advenimiento de la Gran Guerra supuso cierto receso en la producción del género. La aventura tomaría la posta: los grandes desplazamientos, los espacios abiertos, exóticos, de campo traviesa, la distancia cultural entre los personajes y el espionaje, van a utilizar la plataforma investigativa para otros misterios y dilemas, menos enclavados en una ciudad que los defina y con las miras bien puestas en la ideología. Pero al inaugurarse la Guerra Fría hubo que enfrentar una nueva disyuntiva: mantenerse en la tradicion moralizante y crítica, o renovarse al ritmo de la violencia, la corrupción y los cambios políticos de un mundo cada vez más convulso y agónico, prisionero de la amenaza de la bomba y desorientado de cara a un nuevo milenio.

Los distintos movimientos sociales, la lucha ideológica, las repercu- siones de los conflictos bélicos en Asia (Corea, Vietnam), los derechos civiles de las minorías, la mano dura del Estado y los regímenes autoritarios acabaron devolviendo a la ciudad su estatus de gran escenario. Ni la estricta ética de Marlowe, ni la psicologizante investigación de Maigret, ni todo el cinismo junto de Sam Spade alcanzaban para los aires que corrían en los días de la Guerra Fría. Tenida más como una fuerza paranoica y represiva, antes que analítica y científica, la policía dejó el combate del crimen en manos de ciudadanos comunes y corrientes. Poco va a importar que exista o no una eficiencia por parte de las fuerzas del bien para hallar a los responsables y reinstaurar el orden, pues el centro dramático de los relatos va a abandonar la peripecia investigativa para instalarse en la exploración del crimen, de la violencia, de la corrupción. Es decir, empiezan a importar los resortes que mueven al delito a personas alejadas de los círculos malhechores. En este tiempo, como señala Giardinelli, el policial va a ocuparse de plantear "crímenes trascendentes a partir de hechos y personajes mundanos" (Giardinelli 1984). A través de una amplísima gama de delitos que podían ir desde planes para destruir la isla de Manhattan hasta peleas de taberna, el relato policial va a densificarse arropado de filosofía para dar cuenta del inmensísimo temor a nosotros mismos tras la exposición de horror y la contabilidad de los saldos finales de la Segunda Guerra. 
Julian Symons, uno de los más ilustres exponentes de este filón, diría:

Lo que más me inquieta de nuestra época es la violencia que se oculta tras un rostro respetable: el burócrata servil planeando cómo liquidar judíos; el juez que defiende con pasión la pena capital; el niño obediente que mata por diversión.

John Le Carré completa la radiografía de este tiempo desconcertante poniendo en boca de Alec Leamas, el espía que surgió del frío, el remate final: "Se necesita ser un héroe para ser simplemente una persona decente".

A partir de este momento, el policial va a diluirse para impregnarlo todo, o casi todo: las historias de espías, de superhéroes, de misterio, de suspenso, de terror. Así, el dato escondido, el enigma, el falso culpable, el método científico como arma de combate, la ciudad como escenario, la razón como emblema, el red herring, el whodunit, entre otros ingenios, pasarían a integrar el paisaje de diversas tramas y contextos.

Para cuando llegan los años setenta el policial es una especie de dinosaurio inmenso, impreciso en su definición, desigual en sus contenidos, complejo en sus patrones y menos abundante en su tiraje. Sin embargo, no va a perder su inmenso arraigo. La respuesta a la necesidad de un nuevo giro de tuerca para renovar su talante la encontrará en el vehículo de masas por excelencia de la segunda mitad del siglo XX: la televisión.

\section{Los soportes de tránsito}

El tránsito del papel a la pantalla chica parecía lógico. Desde sus inicios, los formatos populares han sido los más cómodos y dúctiles para un género como el policial que bebe de la cotidianidad y genera puntos de coincidencia donde el público se reencuentra con claves universales que dan cuenta de sus más íntimos miedos y secretos, de sus angustias y de sus monstruos más personales.

Brunori considera que la visión de un mundo cerrado e inamovible, rigurosamente dividido en compartimientos estancos, pasó del folletín al policial (Brunori 1980). El mundo idealizado de la revolución, que aparentemente consentía héroes pillos como el Jean Valjean de Los miserables, ofrecía una conexión con el público masivo, pero escondía también las sanciones que emanaban del orden convencional. Ya en el folletín operaban la redención y la sanción para quienes contravenían las normas y las formas, el equilibrio social y la profanación de los valores elementales. De aquí que las pautas del policial mantengan una sólida conexión con el formato y el imaginario popular, vinculándose con el contexto y las emociones de la experiencia común.

Nos gusta pensar que el carácter lúdico del esquema policial también resulta vital para la subsistencia del género. Planteado el misterio como un juego de ajedrez donde se sabe de antemano quién triunfará, el interés 
reside en las formas de ganar, en el ingenio multiforme y la oportunidad para los enroques, en el efecto sorpresa, que otorgarían al lector una sensación de poder-hacer y querer-creer que se puede cambiar el estado de las cosas. Es decir, estamos ante una forma vicaria de vivir las imposibilidades de un mundo cada vez más alborotado. El hombre de la calle, como anota Brunori, que busca diversión o una moraleja consoladora, se sentiría atraído por las excepcionales cualidades del detective por la misma razón que los apasionados de la novela por entregas abrazaban los ideales de los héroes cándidos y puros.

Un tercer factor que habría favorecido el desarrollo y la persistencia del policial es el cariz mítico cifrado en sus historias. El policial reproduce el choque de fuerzas más antiguo y próximo a la humanidad: el mal derrotado por el bien, el orden que se impone sobre el caos. En estos relatos, quien se sale del buen camino paga tarde o temprano las consecuencias y las vicisitudes del héroe sirven para exorcizar el incremento de hostilidad y criminalidad de un mundo que ofrece más incertidumbre que placer. Jordi Balló y Xavier Pérez, en La semilla inmortal, consideran que el ciclo mesiánico del Nuevo Testamento nos ha heredado toda una concepción del mundo que opera como referencia ineludible al momento de trazar historias, pues surge de la necesidad de un líder por parte de una comunidad en crisis para restablecer el orden. "La comunidad mantiene la memoria de una pasada edad de oro, un paraíso perdido que sólo la intervención del líder mesiánico puede devolver" (Balló y Pérez 1997). De esta forma, el mundo moderno reemplazó a la Providencia por la Policía y el cariz mítico se encarnó en el investigador, nuevo redentor de los justos y salvador de los inocentes.

La industria editorial fue la más prolífica y popular productora de entretenimiento durante la primera mitad del siglo XX. Los libros y revistas policiales de las décadas medias ya eran masivas y se hacían en papel pulpa, amarillento, barato y poco vistoso, pero garantizaban tiraje y consumo. El arribo del cine, y posteriormente de la televisión, va a robarse la imaginación soberana de los consumidores, por lo que el paso a este nuevo soporte de expresión no asoma como extraño.

Mudarse a la pantalla chica va a suponer una renovación en varios sentidos para el policial. Si bien la lógica del relato de género va a permanecer, las posibilidades del medio le otorgarán un dinamismo, una plasticidad y un realismo que acentuarán sus tópicos y marcas registradas: la sangre, la pólvora, el disparo certero, el vértigo, la sensación de peligro, el efecto sorpresa, la peripecia física. Para decirlo de una vez, las fibras sensibles que conectan con el policial van a verse especialmente estimuladas ante la experiencia audiovisual que ofrecen las series televisivas a un público ya 
adiestrado en estas lides gracias al cine, especialmente el de clase B. La lógica episódica o por entregas se verá traducida en el formato de las series, que narrarán una vez por semana sus aventuras, apelando a las mismas viejas claves folletinescas de la postergación, la anticipación y "la percha en el abismo", es decir, la acción suspendida hasta el nuevo episodio.

No obstante ciertas características temporales, la televisión va a aportar al género su afición por los modelos de la cultura de masas, su visión paródica de ciertas estructuras novelescas, su propia creación de estereotipos, el empleo de los discursos populares y marginales; y el eclecticismo, el pastiche, la contaminación genérica y esa mirada superior, burlona y desacralizadora que lanzan sobre lo que durante muchos años fue la semilla del género: el enigma. Más que una ruptura radical, el policial televisivo continuará la ascendente evolución iniciada por sus antecesores, junto a la insistencia del tratamiento racional en clave de investigación, el espectáculo y el carácter reporteril que van a ser elementos que se integren a la narración.

\section{Del autor al productor}

Los policiales de televisión deben su éxito no a los escritores que fraguaron sus tramas, sino al ojo certero de pro- ductores que supieron conducirlas. En televisión, la denominada 'autoría' se aleja de la figura del escritor para afiliarse a la sensibilidad y oportunidad de productores que acaban creando estilo, escuela e incluso marca. ${ }^{2}$ Quien dirige es un operador que traduce esta visión, al punto de que los directores cambian indistintamente en cada episodio y podemos ver repartidos sus nombres en distintas series de diversa orientación.

Latinoamérica ha bebido principalmente de la producción policial de los Estados Unidos y es a partir de ella que se han forjado preferencias, estilos y formas de consumo. Hay una propuesta de mundo, un life style, unos valores y principios que el televidente promedio reconoce $y$ ha incorporado a su experiencia televisiva. Las series norteamericanas han conseguido fraguar no solo una idea general del mundo y sus valores a través de sus historias, sino que también le han dado forma a un género que evoluciona y se complejiza de acuerdo con las posibilidades que ofrece la pantalla chica.

Si hubiera que rastrear al padre de este trabajo, quien asoma como pionero es Quinn Martin (1927-1987), productor de las más exitosas series de los años sesenta y setenta. Lo interesante de Martin es que va a construir relatos anclados en la lógica de los años treinta, intentando reproducir de manera

2 Es el caso de Dick Wolf y su Law E Order o Jerry Bruckheimer y su CSI, entre otros. 
fiel y atractiva los usos y rutinas policiales así como los motores del crimen (Edgerton 2007). Es decir, si Dashiell Hammett se había ocupado de los delitos no en clave de enigma, sino en función de los vicios y pecados de la gente común y corriente, Martin va a procurar lo mismo dándole un rostro y unas cualidades particulares a los malhechores y sus móviles. Coincidió con Hammet, además, en una vocación por los espacios urbanos, anclando nuevamente el relato en un espacio moderno y particular, pero capaz de registrar al mismo tiempo las vicisitudes generales del mundo.

Las posibilidades del soporte y la búsqueda de nuevos aires van a lograr que el policial desarrolle en la pantalla chica una serie de matices. Encontraremos desde el clásico detective privado, al mejor estilo de los crímenes de Poe o Conan Doyle, hasta los policías de fuste, institucionalmente comprometidos con el aparato del orden (to protect and to serve); desde el crimen psicológico, con marcas de psicoanálisis y psicología clínica que dan cabida en la narración también al mundo interior de los criminales, hasta los relatos carcelarios, donde la redención y la purga son clave fundamental de un género que se esmera por limpiar las heridas sociales y mostrar los estragos de un comportamiento desviado.

Si bien el punto de vista que se presenta es el de los chicos buenos, con el tiempo los personajes van a dotarse de una dimensión mucho más terrena, de modo tal que trastocarán la simplificación maniquea de policías y ladrones para presentar seres complejos cuyas fechorías pueden merecer comprensión, conmiseración, lástima o justificación; pero también guardianes probos del orden no tan inmaculados ni eficientes en la consigna de proteger y servir, siempre con algún dilema, alguna tara, alguna marca o un pasado que los atormenta.

Si bien Martin va a ser el precursor del Hammet way en el policial televisivo, pronto las series van a distanciarse de los modos de la novela negra en lo que al tratamiento del crimen se refiere. Si los primeros relatos policiales abordaban el crimen en lo que hemos llamado un 'universo vacío' para asegurar la fórmula de resolución, los relatos televisivos van a verse en la necesidad de plantear su propio universo y en este proceso el realismo y el maniqueísmo van a aparecer en tensión permanente. Por ejemplo, mientras más verosimilitud se busque imprimir al trabajo policíaco, más riesgos se corre de atentar contra la tensión y el suspenso que son condición básica del género. Y viceversa, la búsqueda de mayor atractivo en la acción puede hacer perder los vínculos con la realidad. La búsqueda de este balance parece constituir el principal motor de actualidad y renovación del policial televisivo. Normalmente, desde el punto de vista narrativo, zanjamos esas particularidades utilizando la etiqueta de 
'convenciones de género', pero lo interesante del policial de televisión es que va a ser capaz de plantear tantas convenciones como series se propongan, gracias a la hibridación con otros géneros como la aventura, el melodrama o la comedia, que van a potenciar de manera notable la forja de estos universos ficcionales.

\section{Los duros de la tele}

Enmarcada dentro de lo que se conoce como el police procedural, en octubre de 1959 la compañía CBS encargó a Quinn Martin un piloto de dos capítulos de Los intocables (The untouchables), una de las series clásicas del género $\mathrm{y}$, probablemente, el punto de partida del policial de televisión tal como se le conoce hoy. Como resultado de estos episodios, la cadena ABC realizaría la serie entre los años 1959 y 1962, centrando cada capítulo en la lucha que Ness y sus hombres libraban contra la mafia. Con Los intocables, Martin perfiló un diseño de producción que privilegiaba la solidez actoral de sus protagonistas y dejaba los libretos en manos de reconocidos escritores del género. También impuso un modelo de presentación para los programas: pista musical compuesta especialmente y una voz de narrador que anunciaba el nombre de la serie.

Tras el éxito de Los intocables, Martin se embarcó en un proyecto personal que tituló El fugitivo (The fugitive). Los capítulos no pueden considerarse precisamente policiales, pero estaban llenos de situaciones dramáticas tan colmadas de suspenso y tensión que en el episodio final de la serie el doctor Kimble no solo capturó al hombre de un solo brazo, sino al 72 por ciento de los televidentes de los Estados Unidos (Edgerton 2007). Avalado por el suceso de estos programas, Martin se embarca en El FBI (The FBI), con el actor Efrem Zimbalist Jr., a quien el propio Edgar Hoover eligió como mejor representante del agente especial. Los guiones se basaron en casos de archivo de la agencia federal y eran una declaración obvia de patriotismo e integridad. Como dato anecdótico queda que Zimbalist Jr. es responsable de la famosa postura del agente que apunta con las dos manos mientras grita “iAlto, FBI!”, frase obligada que, sin embargo, no figura en el protocolo de los agentes de bureau.

Cannon fue la primera serie que tuvo como protagonista a un detective privado. Bajo la figura de un private eye, el actor William Conrad daría vida a Frank Cannon entre 1971 y 1976 con gran éxito. Quizá gracias a él la marca registrada de los policiales de los setenta va a ser la utilización, a contracorriente, de protagonistas viejos, gordos o feos. Esta tendencia la iniciaría Barnaby Jones, protagonizada por Buddy Ebsen entre 1973 y 1980. La historia del detective que volvía del retiro para investigar la muerte de su hijo, abriría las puertas a Karl Malden en Las calles de San Francisco (San Francisco streets) y Telly 
Savalas en Kojak. En estas dos últimas series, Martin sumaría a la solidez interpretativa y los guiones ${ }^{3}$ nuevas técnicas de filmación que ofrecieron una experiencia inédita de las ciudades donde ocurrían las tramas.

Los shows producidos por Quinn Martin marcarían no solo los años sesenta y setenta con su estilo sobrio y duro, sino que sentarían bases fundamentales en la realización de estos programas. Martin perfeccionó la fórmula del episodio televisivo de una hora al pautar la duración de los bloques dramáticos (marcados por el corte comercial), el número de secuencias de acción en cada uno de estos bloques, el uso de la ciudad como plató (locaciones reales), así como una notable maestría para la postergación que aseguraban la permanencia de la audiencia (Butler 2009).

La influencia de Martin se dejaría sentir de distinto modo en escritores y productores de televisión. Dos series se alzan como principales tributarias, Hawaii 5-0 y Columbo, pero a la vez abren nuevas vías. En la primera, producida por Leonard Freeman, se ensayó exitosamente el protagonismo colectivo, aun cuando Jack Lord en el papel del oficial McGarrett llevaría la batuta desde 1968 hasta 1980. Hasta hoy la serie policial de más larga du- ración. Por su parte, Columbo (19711978) va a ser la primera en arriesgar los límites del género. Peter Falk hizo que el personaje concebido por Richard Levinson y William Link escapara al molde original. Su Columbo nunca portó un arma, nunca tuvo un compañero, pero sí una esposa que nunca apareció en pantalla, un perro moribundo que vivió los ocho años que duró la serie, era despistado y olvidadizo, no actuaba de acuerdo a los estándares del procedimiento policial y exhibía un humor extraño para este tipo de personajes. Columbo se convirtió en un personaje popular y la bendición de la audiencia autorizó nuevas posibilidades de expresión y experimentación.

A partir de los años ochenta, la televisión va a ofrecer una gran diversidad de proyectos que se diferencian básicamente por sus estilizadas propuestas vinculadas a la cultura popular (mucha moda, mucha música, muchos jóvenes, mucha sensualidad). El representante arquetípico es, sin duda, Miami Vice (1984-1989), creado originalmente como un programa para la audiencia de MTV. Este germen fue gravitante para el desarrollo del proyecto, pues el requerimiento específico de un tipo de imágenes y sonido obligó a los realizadores a convertir

3 El escritor Joe Gores ganaría un premio Edgar (el mayor galardón entre los escritores de misterio) por uno de sus capítulos de Kojak. Gores también escribió varios capítulos de Columbo y, ya en los ochenta, realizó varios guiones para Magnum P.I. y Remington Steele. 
la cinética y el deslumbramiento técnico ${ }^{4}$ en tópicos tan importantes como el argumento y los personajes; de hecho fueron colocados al mismo nivel. Anthony Yercovich, escritor y productor, decía que Miami Vice fue concebido para poner en movimiento la emoción, porque la razón se movía demasiado lenta para los años ochenta.

Miami Vice representa un hito porque marca la pauta y el estándar que las series de televisión deberán seguir en adelante para competir por la audiencia. Pero, sobre todo, porque se convirtió en un fenómeno social que conectó efectivamente con el imaginario de la audiencia al punto de obligar a sus creadores a operar en base a ello. Los primeros episodios presentaban elementos del procedimiento policial frecuente, rutinas, temas y tratamientos, pero pronto debieron ser abandonados para construir un estilo propio nutrido en base a la cultura popular de la época. Gran peso tuvieron la música y la moda, por ejemplo. Además de los distintivos sintetizadores de Jan Hammer, cada episodio incluía temas del momento a cargo de músicos como Phil Collins, Sheena Easton o Frank Zappa. Sus protagonistas, los actores Don Johnson y Philip Michael Thomas, popularizaron los lentes Ray Ban, las camisetas debajo de sacos remangados e impulsaron un renovado furor por el art decó, gracias a las vistosas locaciones que exhibía la serie.
Quizá por todos estos añadidos y posibilidades de mercado, la producción de series va a tornarse millonaria, siempre a la búsqueda de nuevos públicos. La hibridación entre el policial clásico y otros géneros va a abrir nuevas posibilidades. Recordemos Moonlighting (1985-1989) y su cuota de comedia y tensión sexual entre los protagonistas. O Hill Street Blues (19811987) y su exploración en el melodrama, con líneas dramáticas que no se resolvían en cada episodio sino que se postergaban a lo largo de la temporada, con preguntas recurrentes en el orden moral del tipo ¿qué es lo correcto?, o ¿qué he hecho?, tan heredadas de la telenovela y tan útiles luego a series como NYPD Blue (1993-2005) que anclan gran parte de su desarrollo dramático en las relaciones personales.

De cualquier forma, junto con propuestas más pop, la figura del investigador, sea agente de la ley, detective privado o sujeto de a pie, va a permanecer y evolucionar junto a su público. La inclusión de mujeres en roles protagónicos, por ejemplo, aumentó a la par que se dio una mayor y mejor inclusión de estas en espacios antes tenidos como eminentemente masculinos. En los policiales de televisión, las mujeres pasaron de femme fatale y vampiresas arribistas a detectives, abogadas o periodistas que luchan por encontrar la verdad y hacer justicia. El primer personaje femenino de relevancia en una

4 Miami Vice fue de las primeras series en ser emitidas con sonido estéreo. 
serie policial fue probablemente la sargento Vicky Hicks de Fraud Squad (1969-1970), pero no sería sino hasta Charlie's Angels (1976-1981) que se legitimaría la autonomía femenina en estos predios. Sin embargo, los argumentos previsibles y la gran maquinaria publicitaria que soportó sus años al aire hacen que todavía hoy se discutan sus méritos.

Serán Cagney \& Lacey (1982-1988), dos eficientes detectives de Nueva York, las que den carta de ciudadanía al policial protagonizado por mujeres y quienes compaginen el crimen con tópicos como la maternidad y las tareas de un ama de casa. Después vendrían Olivia Benson, la agente de Law $\mathcal{E}$ Order: UVE, o Lily Rush, de Cold case, de gran peso protagónico y más próximas al talante policial típico del género. Ambas se comprometen emocionalmente con las víctimas de sus casos, mujeres, niños y hombres que han sufrido abusos, al estar a cargo de unidades que enfrentan casos escabrosos y muy próximos a los temas de familia. Hace poco, la cadena Fox estrenó Murder club, un policial ciento por ciento femenino, que mezcla los problemas sentimentales de sus cuatro protagonistas, a la manera de Sex and the city, con la investigación de asesinatos. En la serie, una inspectora de homicidios, una examinadora médica, una reportera y una asistente del fiscal de distrito deben también perseguir a un homicida serial que cose las bocas de sus víctimas.

\section{Hermeneutas, científicos y locos}

El policial de televisión ha sabido recrearse constantemente para encontrar nuevas audiencias y de esta manera acortar la brecha entre ficción y realidad, no para anular la diferencia, sino para potenciarla y habilitar nuevas formas de narración. Hay al menos dos procesos que Luis Fanlo ${ }^{5}$ encuentra significativos dentro de esta evolución: el tránsito del detective hermeneuta (Columbo, Baretta, Law \& Order) al detective científico (CSI, Criminal minds, Bones) y del policía incorruptible y encarnación del bien (Kojak) al policía con alto grado de conflictividad social o personal (NYPD Blue, The Shield). El hermeneuta es capaz de esclarecer el crimen apelando a la intuición y la experiencia, es más listo que el bandido y consigue hacerlo caer en una trampa para confesar su culpa. El científico, por su parte, resuelve el crimen apelando a un conjunto de saberes y técnicas científicas, se mueve en el reino de la evidencia, del positivismo más radical, donde lo que a veces aparece como intuición bien po-

5 Luis Fanlo es doctor en Ciencias Sociales de la Universidad de Buenos Aires (UBA) y dirige un esmerado blog dedicado a las series de televisión: $<$ http://luisgarciafanlo.blogspot. com>. 
dría calificarse de enciclopedismo. El policía incorruptible y encarnación del bien es cómplice y guía del espectador, lo educa en el tránsito de la sombra a la luz, pero el que carga con una conflictividad social o personal se construye básicamente como antihéroe, puede moverse en el campo de la hermenéutica (Monk) o la ciencia (Numbers) pero asiste al trabajo como quien va al analista para sobrevivir todos los días.

Lo que se habría producido, según Fanlo, es una ambivalencia donde lo bueno y lo malo, lo tradicional y lo nuevo, conviven, intercambian roles, se amalgaman y se distribuyen el centro de la pantalla. Hoy el deslumbramiento científico que exhiben las series de televisión puede ser protagonista del mismo modo que un criminal puede ser aceptado por justiciero y hermeneuta (el asesino en serie es paradigmático en este sentido), aunque el discurso moral no permita abrazarlo con todo el afecto que uno quisiera.

Dexter ejemplifica de manera arquetípica esta némesis del discurso y la práctica criminalística. Es la historia del personaje del mismo nombre que de niño fue brutalmente reeducado por su padre al ser descubierto en plena matanza de animales. De adulto, y ya convertido en forense de la policía, Dexter emprende una cruzada personal para eliminar a homicidas cuyos crímenes atentan contra sus códigos del buen matar, si cabe el término: violadores, pedófilos, depredadores sexuales. Su modus operandi consiste en atarlos a una mesa y descuartizarlos mientras están vivos. De la escena del crimen se lleva un souvenir: unas gotitas de sangre que perpetúa entre dos pequeños vidrios y que esconde en los ductos de ventilación de su departamento. Aquí, el clásico planteamiento de la serie policial en clave de blanco o negro ha movido su centro de gravedad a las áreas grises.

Algo parecido empieza a ocurrir en lo que respecta a su narrativa. Algunos componentes empiezan a ser alterados en su función. Por ejemplo, la elipsis y el uso del tiempo. A través de estos recursos podemos hacer fluir más rápidamente una historia. En CSI las zonas en off son varias y en las porciones en on los testigos hablan rápido, los acusados se desmoronan enseguida, los forenses llegan a tiempo a la escena, los jueces dictaminan pronto, los resultados de balística ocurren en cuestión de minutos. Esto forma parte del pacto con el espectador: se suspende la realidad y se conviene en un tiempo diegético que debe ajustarse a cuarentaicinco minutos de transmisión. En la serie 24 cada episodio de una hora representa una hora continua de acción de la trama. Cada temporada compuesta por veinticuatro capítulos conforma un día en la vida del agente Jack Bauer. Y si nos fijamos en una serie como The wire, encontraremos la confirmación de que algo está sucediendo. 
The wire no sintetiza la acción, desmenuza la inercia. ${ }^{6}$ Es la antítesis de las series policiales en cada uno de sus lineamientos, está basada en el detalle, un solo caso puede durar una temporada completa. Si en otras series los protagonistas hablan demasiado, nunca duermen, lo explican todo en voz alta, verbalizan sin necesidad para integrar al espectador, en The wire trabajan en silencio, se quedan dormidos cuando tienen sueño, fallan y parece importarles muy poco lo que hayan planteado Quinn Martin y todos los que vinieron después de él. En la primera temporada, este grupo de policías de Baltimore intenta desbaratar una red de tráfico de drogas, pero los testigos no hablan, los acusados no se desmoronan, los policías tienen familia y problemas para llegar a la escena del delito a tiempo, los jueces están más interesados en sus carreras que en la justicia, balística no funciona ni bien ni a tiempo, la burocracia es agotadora, los micrófonos escondidos acoplan, los sargentos se emborrachan, el café está frío y los malos, muchas veces, son sujetos a los que podríamos confiarles nuestras casas un fin de semana. No hay síntesis en la trama, no hay finales sorpresivos. Es una larga película de trece horas de duración, repartida en una docena de capítulos.
Todo esto es parte de la dinámica y el juego que plantea el género policial en la televisión. Intentar definirlo resulta cada vez más complejo. ¿Se necesita una ciudad para montar un policial? ¿Hace falta un detective? ¿El enigma es requisito? ¿Qué hay del procedimiento? Pensemos, por ejemplo, en una serie emblemática de los últimos años como es House MD. Gregory House es Sherlock Holmes trasmutado en médico de diagnóstico, cínico y ácido como Sam Spade, adicto como Marlowe, no al whisky sino al Vicodin, sus pacientes son víctimas de un misterioso asesino que no habita en la ciudad, sino en sus propios organismos. Podríamos calificarlo como hermenéutico, pero también como un tipo con alta conflictividad consigo mismo y los demás. Entonces, ¿en qué consiste el policial de hoy?... Cada vez más es todo y nada al mismo tiempo, acaso el próximo enigma por resolver.

\section{Bibliografía}

BAlló, Jordi y Xavier Pérez (1997). La semilla inmortal. Los argumentos universales del cine. Barcelona: Anagrama.

Bertrand, Claude (1992). La televisión de Estados Unidos. Madrid: Rialp.

6 Algunos ven un antecedente remoto pero válido en la serie Dragnet (1952-1957), que retrataba con solvencia la rutina y el aburrimiento de algunos aspectos del trabajo policial. 
BRUNORI, Vittorio (1980). Sueños y mitos de la literatura de masas. Barcelona: Gustavo Gili.

ButLer, Jeremy (2009). Critical methods and applications. Nueva Jersey: Mid Atlantic Books \& Journals, Inc.

Edgerton, Gary (2007). The Columbia history of American television. Nueva York: Columbia University Press.

FANLO, Luis. Top mejores detectives. $<$ http://luisgarciafanlo.blogspot. com/2009/10/genero-policial-y-television.html>. [Consulta: 11 de junio del 2009].
Giardinelli, Mempo (1984). El género negro. México: Universidad Autónoma Metropolitana.

Narcejac, Thomas (1986). Una máquina de leer: La novela policíaca. México: Fondo de Cultura Económica, Colección Popular 343.

Padura, Leonardo (2000). Ensayos acerca de la novela policíaca en Iberoamérica. La Habana: Ediciones Unión.

Symons, Julian (1992). Historia del relato policial. Barcelona: Bruguera. 